\title{
Kalın ve katmanlı kompozit plakaların temel doğal frekansının mekanik özelliklerin küçük değişimlerine duyarlılığı
}

\author{
Sensitivity of fundamental natural frequency of thick and laminated composite plates in \\ small changes of mechanical properties
}

\begin{abstract}
Murat KARA*1,a
${ }^{1}$ Bolu Abant İzzet Baysal Üniversitesi, Mühendislik Fakültesi, Makine Mühendisliği Bölümü, 14000, Bolu

• Geliş tarihi / Received: 24.07.2020 • Düzeltilerek geliş tarihi / Received in revised form: 12.02.2021 - Kabul tarihi / Accepted: 22.03 .2021

Öz

Kompozit plakaların istenilen özelliklere göre tasarımı genellikle deneme yanılma ile yapılmaktadır. Bu durum elde edilen nihai tasarım sürecini uzatmaktadır. Dolayısıyla tasarım sırasında istenilen tasarım amaç fonksiyonu üzerinde etkili tasarım parametrelerin belirlenmesi oldukça önemlidir. Bu bağlamda duyarlılık analizi sıklıkla kullanılan yöntemlerden birisidir. Bu çalışmada farklı kalınlıklardaki kalın katmanlı kompozit plakaların temel (birinci) doğal frekansının duyarlılık analizi gerçekleştirilmiştir. Fiber ve fibere dik yöndeki elastisite modülü ve üç yöndeki kayma modülleri tasarım parametreleri olarak seçilmiştir. Ardından sonlu elemanlar tabanlı Monte Carlo simülasyonu ile tasarım parametrelerinin kombinasyonuna karşılık gelen doğal frekanslar hesaplanmıştır. Daha sonra duyarlılık analizi gerçekleştirmek amacıyla matematiksel bir model oluşturulmuştur. Sonuçta kalınlığa bağlı olarak temel doğal frekansın duyarllı̆ı̆ 1 elde edilmiştir.
\end{abstract}

Anahtar kelimeler: Doğal frekans, Duyarlılık analizi, Kalın kompozit plaka, Serbest titreşim

\begin{abstract}
The design of composite plates according to the desired properties is usually performed by trial and error. This prolongs the final design process. Therefore, it is very important to determine the effective design parameters on the desired design objective function in design processes. In this regard, sensitivity analysis is one of the frequently used methods. In this study, the sensitivity analysis of the fundamental (first) natural frequency of thick layered composite plates with different thicknesses was performed. The elasticity modulus perpendicular to the fibre and among the fibre and the shear modules in the three directions are selected as design parameters. Then, natural frequencies corresponding to the combination of design parameters were calculated with finite element based Monte Carlo simulation. Next, a mathematical model was constructed to perform. As a result, the sensitivity of the fundamental natural frequency was obtained depending on the thickness.
\end{abstract}

Keywords: Natural frequency, Sensitivity analysis, Thick composite plate, Free vibration

*a Murat KARA; kara.murat@ibu.edu.tr, Tel: (0374) 2541000 (4935), orcid.org/0000-0001-5798-9014 


\section{Giriş}

Kontrol edilemeyen küçük değişkenlikler olarak tanımlanan belirsizlik, vibro-akustik uygulamalarda oldukça sık olarak karşılaşılan bir fenomendir (Kompella ve Bernhard, 1993). Titreşim problemlerinde belirsizlik genellikle ilk şartlar ve sınır koşullarındaki değişkenliklerden, geometrideki farkl1liklardan veya çevresel faktörlerden kaynaklanmaktadır. Belirsizlikler yapıların serbest ve zorlanmış titreşim cevaplarını büyük oranda değiştirdiğinden tasarım aşamasında küçük değişikliklerin titreşim cevapları üzerindeki etkisinin belirlenmesi oldukça önemlidir. Bu gibi durumlarda duyarlılık (hassasiyet) analizi s1k olarak kullanılmaktadır (Fox ve Kapoor, 1968; Arora ve Haugt, 1979; Adelman ve Haftka, 1986; Kengtung, 1986; Grenestedt, 1989; Hyer ve Lee, 1991; Mateus vd., 1991; Soares vd., 1995). Literatürde serbest titreşim cevabının duyarlılık analizi konusundaki en erken çalışmalardan biri Fox ve Kapoor (1968) tarafindan gerçekleştirilmiştir. Fox ve Kapoor temel (birinci) doğal frekansı maksimum, sistem kütlesini ise minimum olarak elde etmek için gerekli geometrik büyüklükleri duyarlılık analizi ile elde etmişlerdir.

Kompozit yapılar günümüzde köprülerde, havacılık sektöründe oldukça sık olarak kullanıldığından bu yapıların analizi oldukça önemlidir. Kompozit malzemelerde yukarıda belirtilen belirsizlik sebeplerine malzeme özelliklerindeki değişkenlikler ya da delaminasyonlar eklenmektedir. Kompozit yapılar üzerine yapılan araştırmaların yaygınlaştığı 1980'lerden itibaren kompozit yapıların duyarlılık analizi en iyileştirilmiş (optimal) tasarım parametrelerin elde edilmesinde kullanilan yöntemlerden biridir. Bir çalışmada doğal frekansları en iyileştirmek amacıyla ince kompozit plakalardaki açısal oryantasyon ve katman kalınlığ 1 parametrelerini duyarlilik analizi ile belirlemişlerdir (Mateus vd., 1991; Soares vd., 1995). Zak vd., (2003) çok katmanlı kompozit plakalardaki malzeme ve fiziksel özelliklerdeki küçük değişimlerin temel doğal frekans üzerindeki etkisini duyarlılık analizi ile elde etmişlerdir. Sonuç olarak geometrik küçük değişikliklerin mekanik özelliklerdeki değişimlere göre daha etkili olduğu gösterilmiştir. Lima vd., (2010) ve Lee vd., (2013) duyarlılık analizini sandviç kompozit plakalardaki serbest ve zorlanmış titreşim cevapları için uygulamışlardır. Dey vd., (2015) ise kalın kompozit plakalarda duyarlılık analizi gerçekleştirmek amaciyla üretken rastgele örneklemeli yüksek boyutlu model yaklaşımı (generic random sampling-high dimensional model approach) geliştirmişlerdir. $\mathrm{Bu}$ çalışmada elastisite, açısal oryantasyon ve yoğunluktaki küçük değişimlerin ilk üç doğal frekans üzerindeki etkisi incelenmiştir. Son zamanlarda duyarlılık analizi kompozit plakalarda deleminasyon hatasının belirlenmesi (Zhang vd., 2017; Juhász vd., 2018) ve karbon nanotüplerle güçlendirilmiş kompozit plakalar (Pouresmaeeli ve Fazelzadeh, 2017; Pouresmaeeli vd., 2018) için uygulanmaktadır.

Bilindiği üzere kompozit plakaların kalınlığı arttıkça kayma deformasyonları göz önüne alınmalıdır. $\mathrm{Bu}$ bağlamda yapıların analizlerini gerçekleştirilirken sistemin kalınlığının inceden kalına doğru artmasıyla birlikte kullanılan matematiksel model daha karmaşık hale gelmektedir. Bu durumlarda literatürde ince plaka teorisi, birinci, ikinci ve üçüncü derece kayma deformasyon teorileri kullanılmaktadır. $\mathrm{Bu}$ çalışmada kalın plakalardaki temel doğal frekansın mekanik özelliklerdeki değişimlere karşı duyarlılığ incelenmiştir. Bu bağlamda dört farklı kalınlıkta kompozit plaka incelenmiştir. Tasarım parametreleri olarak kalın plakanın katmanlarının elastisite modülü ( $E_{1}$ ve $E_{2}$ ) ve kayma modülleri $\left(G_{12}, G_{23}\right.$ ve $\left.G_{13}\right)$ seçilmiştir. Her bir tasarım parametresi üç adet örneklenmiş ve tasarım parametrelerinin kombinasyonuna (toplamda $3^{5}$ örneklem) karşılık gelen temel doğal frekanslar hesaplanmıştır. Daha sonra elde edilen doğal frekanslar için bir matematiksel fonksiyon oluşturularak duyarlılık analizi gerçekleştirilmiştir.

\section{Materyal ve metot}

\subsection{Malzeme}

$\mathrm{Bu}$ çalışmada dört farklı kalınlığa sahip basit mesnetli simetrik özel ortotropik katmanlı kompozit plakanın $\left(0^{0}, 90^{0}, 90^{\circ}, 0^{0}\right)$ temel doğal frekansının duyarlılık analizi gerçekleştirilmiştir. Duyarlılık analizinde tasarım parametreleri olarak iki yöndeki elastisite modülleri $\left(E_{1}\right.$ ve $\left.E_{2}\right)$ ve üç yöndeki kayma modülleri $\left(G_{12}, G_{23}\right.$ ve $\left.G_{13}\right)$ seçilmiştir. $\mathrm{Bu}$ tasarım parametreleri üç farklı değer $\quad\left(n \times\left[\begin{array}{lll}0.95 & 1 & 1.05\end{array}\right], \quad n: \quad\right.$ tasarım parametresinin ortalama değeri) ile örneklenmiştir. İncelenen kompozit plakanın mekanik ve fiziksel özellikleri Tablo 1'de verilmiştir.

Çalışmada plakanın dört farklı kalınlık $(h=\{10$, $12.5,20,25\} \mathrm{cm}$ ) durumu incelenmiştir. 
Tablo 1. Kompozit plakanın mekanik ve fiziksel özellikleri

\begin{tabular}{l|c}
\hline Özellik (Sembol) & Değer \\
\hline Plakanın uzunlukları $\left(l_{x} \times l_{y}\right)$ & $1 \times 1 \mathrm{~m}$ \\
Fiber yönündeki elastisite modülü $\left(E_{1}\right)$ & $40 \mathrm{MPa}$ \\
Fibere dik yöndeki elastisite modülü $\left(E_{2}\right)$ & $1 \mathrm{MPa}$ \\
Poisson oranları $\left(v_{12}, v_{13}, v_{23}\right)$ & $0.25,0.25,0$ \\
Kayma modülleri $\left(G_{12}, G_{13}, G_{23}\right)$ & $0.6,0.6,0.6 \mathrm{MPa}$ \\
Yoğunluk $(\rho)$ & $2100 \mathrm{~kg} / \mathrm{m}^{3}$ \\
\hline
\end{tabular}

\subsection{Metot}

Literatürde kompozit plakaların uzunluk ve kalınlık oranı yeterince büyük olduğunda $\left(l_{x} / h>50\right)$ ince plaka teorisinin kullanılabileceği belirtilmiştir (Whitney, 1987). Bu oranın küçük olduğu durumlarda ise kayma deformasyon teorileri kullanılmaktadır. $\mathrm{Bu}$ çalışmada incelenen kompozit plakaların uzunluk kalınlık oranı göz

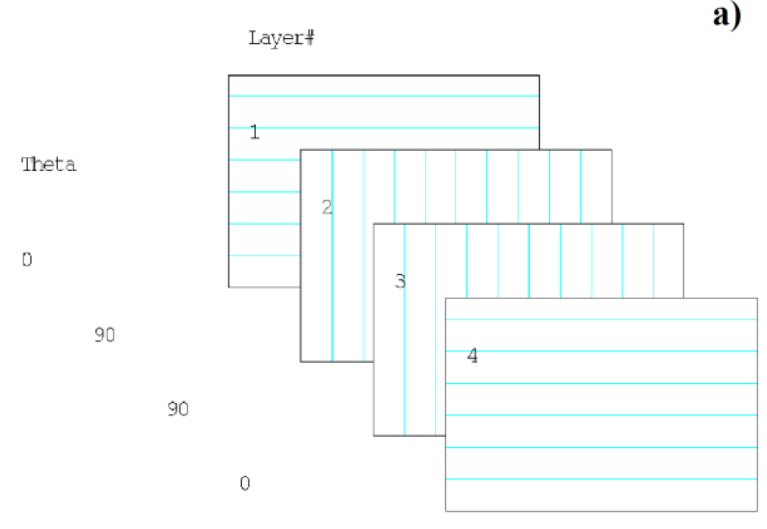

önüne alınırsa kayma deformasyon teorilerinin kullanılması gerektiği açıktır. Temel doğal frekanslar Sonlu Elemanlar Metodu (SEM) ile analizler gerçekleştiren ANSYS 19.1 APDL programı ile hesaplanmıştır. Eleman tipi olarak kalın kompozit plakaları modelleyebilen ve teorik olarak Mindlin-Reissner kabuk teorisini kullanan Shell 181 elemanı kullanılmıștır. Kurulan sonlu elemanlar modeli Şekil 1'de gösterilmiştir. a)

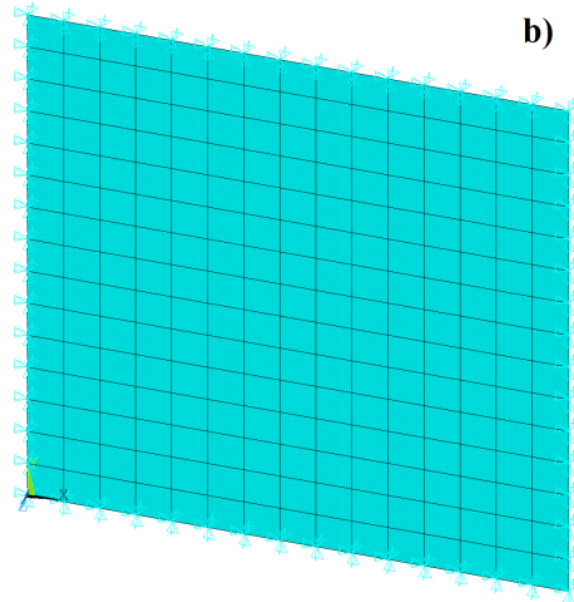

Şekil 1. (a) Kompozit plakanın açısal oryantasyonu (b) Kompozit plakanın sonlu elemanlar modeli

Tasarım amaç fonksiyonu olarak seçilen temel doğal frekansın duyarlı olduğu parametreleri belirlemek için tasarım parametrelerine bağlı aşağıdaki gibi üstel bir matematiksel fonksiyon oluşturulmuştur:

$$
f=a_{1} E_{1}^{a_{2}} E_{2}^{a_{3}} G_{12}^{a_{4}} G_{13}^{a_{5}} G_{23}^{a_{6}}
$$

Burada, $f \mathrm{~Hz}$ cinsinden temel doğal frekans, $a_{1}, a_{2}$, $a_{3}, a_{4}, a_{5}, a_{6}$ ise bilinmeyen katsayılardır. Denklem (1)'de her iki tarafın doğal logaritması alınırsa aşağıdaki regresyon analizi formu elde edilir:

$\ln (f)=\ln \left(a_{1}\right)+a_{2} \ln \left(E_{1}\right)+a_{3} \ln \left(E_{2}\right)+a_{4} \ln \left(G_{12}\right)+a_{5} \ln \left(G_{13}\right)+a_{6} \ln \left(G_{23}\right)$

Denklem (2)'deki bilinmeyen katsayıların elde edilmesi için tasarım parametrelerine karşılık gelen temel doğal frekanslar hesaplanmalıdır. Bu amaçla Monte Carlo simülasyonu kullanılmıştır. Beş tasarım parametresi için üçer adet örneklem kullanıldığından $3^{5}=243$ defa analiz yapılarak temel doğal frekanslar elde edilmiştir. Çalışmada plakanın dört farklı kalınlık $(h=\{10,12.5,20,25\}$ $\mathrm{cm})$ durumu incelendiğinden Monte Carlo simülasyonu her bir kalınlık durumu için tekrarlanmıştır.

\section{Bulgular ve tartışma}

\subsection{Doğrulama çalışması}

Kurulan sonlu elemanlar modelini doğrulamak amacıyla mekanik özellikleri Tablo 1'de verilen 
$0.2 \mathrm{~m}$ kalınlığındaki kompozit plakanın hesaplanan boyutsuz doğal frekansı $\bar{\omega}=\left(2 \pi f l_{x}^{2} / h\right) \sqrt{\rho / E_{2}}$ ile hesaplanarak literatürdeki sonuçlar ile karşılaştırılmıştır. $\mathrm{Bu}$ bağlamda incelenen kompozit plakanın hesaplanan doğal frekansları
$(\mathrm{Hz})$ ve bunlara karşılık gelen boyutsuz doğal frekanslar Tablo 2'de sunulmuştur. Sonlu elemanlar modelinde (SEM) plaka 10x10, 15x15 ve 20x20 adet eleman ile modellenerek sonuçların yakınsaklığı Tablo 2'de \% hata değerleri ile karşılaştırılmıştır.

Tablo 2. Kompozit plakanın boyutsuz temel doğal frekansı $\left(\bar{\omega}=\left(2 \pi f l_{x}^{2} / h\right) \sqrt{\rho / E_{2}}\right)$

\begin{tabular}{c|c|c|c|c}
\hline & Khdeir ve Librescu & \multicolumn{3}{|c}{ SEM (\% Hata) } \\
\cline { 3 - 5 } & $(1988)$ & $\mathbf{1 0 x 1 0}$ & $\mathbf{1 5 x 1 5}$ & $\mathbf{2 0 x 2 0}$ \\
\hline$f$ & & 7.6275 & 7.5954 & 7.5839 \\
\hline $\bar{\omega}$ & 10.854 & $10.981(\% 1.17)$ & $10.935(\% 0.75)$ & $10.918(\% 0.59)$ \\
\hline
\end{tabular}

Tablo 2'de görüldüğü üzere sonlu elemanlar yöntemi ile elde edilen doğal frekanslar literatürdeki sonuçlar ile oldukça uyumludur. Bunun yanında, farklı eleman sayılarında \% hata değerleri incelendiğinde hesaplama sürelerini azaltmak amaciyla \% 1 hata eşik değer olarak kabul edilmiştir. Buna göre kompozit plaka, bundan sonraki analizlerde belirtilen hatanın altında sonuç veren en düşük eleman sayısı olan $15 \times 15$ eleman sayısı ile modellenmiştir.

\subsection{Duyarlılık analizi sonuçları}

Monte Carlo simülasyonu parametrik çalışmalarda oldukça sık olarak kullanılan bir yöntemdir. Bu simülasyonda değişken parametreler uygun dağılımlar ile modellenir ve oluşturulan örneklemlerin tüm kombinasyonlarını kapsayacak şekilde girdi parametreleri sayısal analiz yöntemine beslenir. Sonuç olarak istenilen cevap parametresi (deplasman, hı, gerilme, doğal frekans vs.) girdi parametrelerine karşıllık olarak hesaplanır. Bu yöntemde girdi parametrelerinin uygun bir şekilde modellenmesi için çok sayıda örneklem gerektirebilir. Bu nedenle hesaplama süreleri oldukça uzun olabilir.

$\mathrm{Bu}$ çalışmada sonlu elemanlar yöntemi ile gerçekleştirilen Monte Carlo simülasyonu sonuçlarına çok eğrili regresyon analizi (multiple curvilinear regression analysis) uygulanarak Denklem (2)'deki bilinmeyen katsayılar her bir kalınlık için ayrı ayrı elde edilmiştir. Elde edilen katsayilar Tablo 3'te sunulmuştur.

Tablo 3. Hesaplanan regresyon katsayıları

\begin{tabular}{c|c|c|c|c}
\hline Katsaylar & $\boldsymbol{h = 0 . 1} \boldsymbol{~}$ & $\boldsymbol{h}=\mathbf{0 . 1 2 5} \boldsymbol{m}$ & $\boldsymbol{h}=\mathbf{0 . 2} \boldsymbol{~}$ & $\boldsymbol{h = 0 . 2 5} \boldsymbol{m}$ \\
\hline $\boldsymbol{a}_{\boldsymbol{1}}$ & 279.0495 & 272.3468 & 265.4062 & 177.2606 \\
\hline $\boldsymbol{a}_{2}$ & 0.0194 & 0.0185 & 0.0177 & 0.0197 \\
\hline $\boldsymbol{a}_{3}$ & 0.0162 & 0.0153 & 0.0146 & 0.0137 \\
\hline $\boldsymbol{a}_{4}$ & 0.1026 & 0.1059 & 0.1090 & 0.1309 \\
\hline $\boldsymbol{a}_{5}$ & 0.0564 & 0.0581 & 0.0598 & 0.0748 \\
\hline $\boldsymbol{a}_{\boldsymbol{6}}$ & -0.5000 & -0.5000 & -0.5000 & -0.5000 \\
\hline
\end{tabular}

Elde edilen matematiksel modelin doğruluğunu test etmek amacıyla, $R^{2}$, ayarlanmış $R^{2}$ ve karekök ortalamalı hata değeri (RMSE) değerleri hesaplanarak Tablo 4'te sunulmuştur. $\mathrm{Bu}$ değerlerden $R^{2}$ ve ayarlanmış $R^{2}$ bir değerine, RMSE'nin ise sıfira yakın olması iyi bir eğri geçirme işleminin gerçekleştirildiğini gösterir.

Tablo 4. Hesaplanan $R^{2}$, ayarlanmış $R^{2}$ ve karekök ortalamalı hata değeri (RMSE) değerleri

\begin{tabular}{c|c|c|c|c}
\hline $\begin{array}{c}\text { İstatistiksel } \\
\text { büyüklük }\end{array}$ & $\boldsymbol{h = 0 . 1} \boldsymbol{m}$ & $\boldsymbol{h}=\mathbf{0 . 1 2 5} \boldsymbol{m}$ & $\boldsymbol{h = 0 . 2} \boldsymbol{m}$ & $\boldsymbol{h = 0 . 2 5} \boldsymbol{m}$ \\
\hline $\boldsymbol{R}^{\mathbf{2}}$ & 1.000 & 1.000 & 1.000 & 1.000 \\
\hline Ayarlanmıs $\boldsymbol{R}^{2}$ & 1.000 & 1.000 & 1.000 & 1.000 \\
\hline $\boldsymbol{R M S E}$ & $8.7 \mathrm{E}-08$ & $9.4 \mathrm{E}-08$ & $9.8 \mathrm{E}-08$ & $1.6 \mathrm{E}-07$ \\
\hline
\end{tabular}


Tablo 4'te görüldüğü hesaplanan istatistiksel büyüklükler elde edilen matematiksel fonksiyon ile gerçek verilerin birbirleriyle uyumlu olduğunu göstermektedir.

Son olarak temel doğal frekansın tasarım parametrelerindeki küçük değişimlere karş1
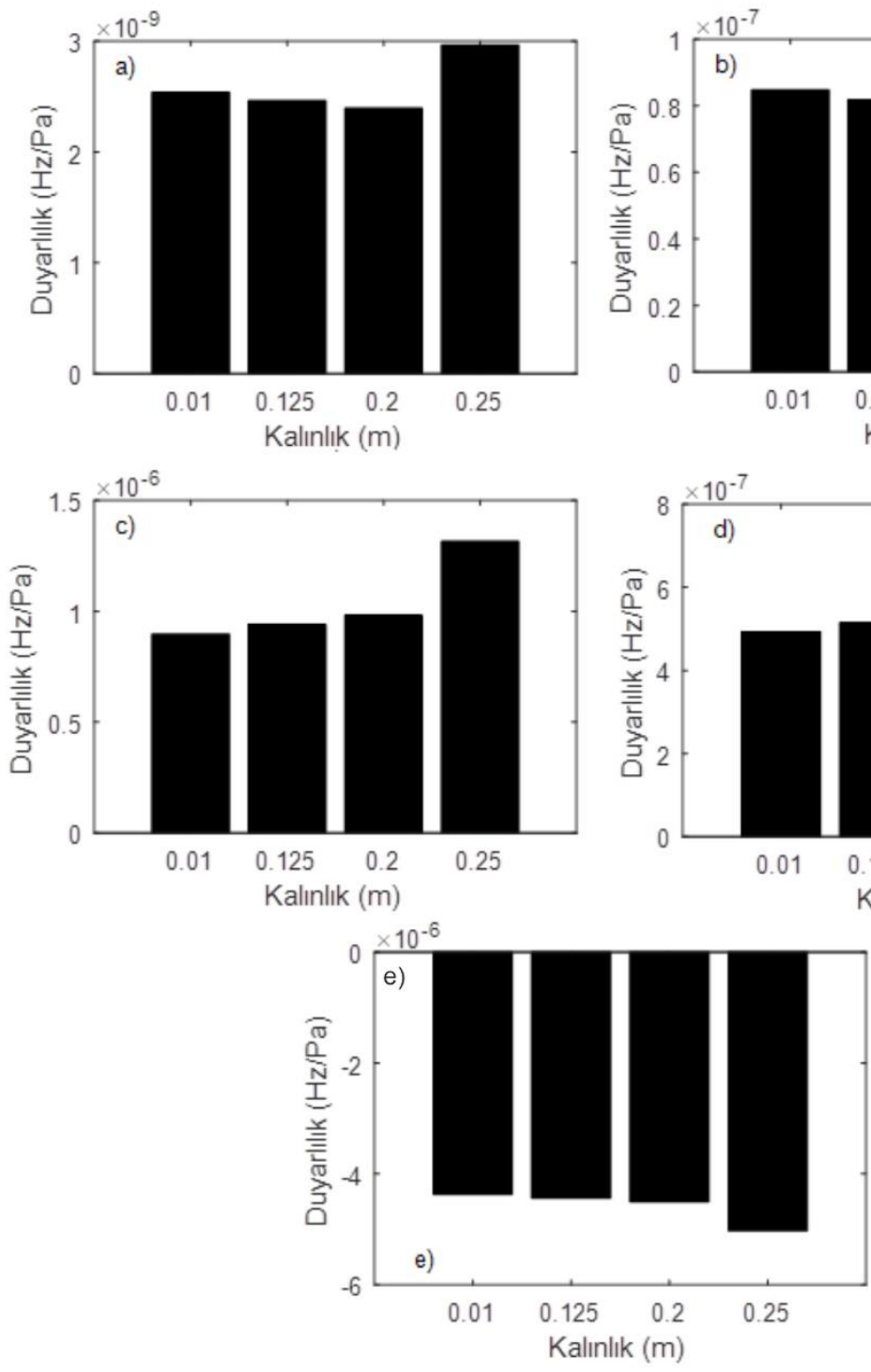
sunulmuştur.

duyarlılı̆̆ farklı kalınlıktaki kompozit plakalar için matematiksel modelin ilgili parametreye göre kısmi türevinin alınmasıyla hesaplanmıştır. Mekanik özellikleri Tablo 1'de sunulan farklı kalınlıklardaki kompozit plakanın tasarım parametrelerine göre duyarlılıkları Şekil 2'de
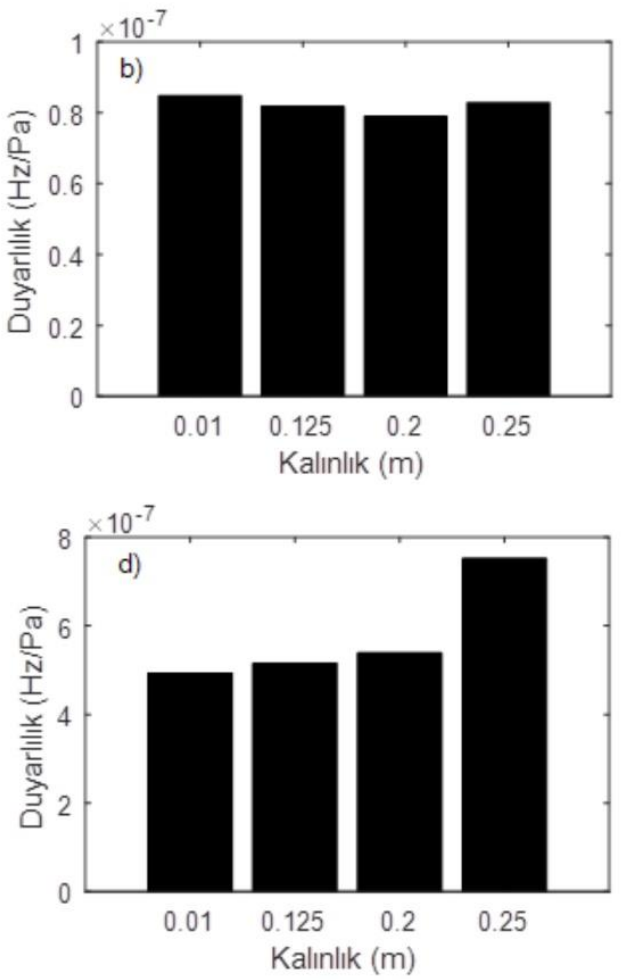

Şekil 2. Kompozit plakanın temel doğal frekansının tasarım parametrelerine göre duyarlılığı (a) tasarım parametresi: $E_{1}(\mathbf{b})$ tasarım parametresi: $E_{2}(\mathbf{c})$ tasarım parametresi: $G_{12}(\mathbf{d})$ tasarım parametresi: $G_{23}(\mathbf{e})$ tasarım parametresi: $G_{13}$

Şekil 2'e göre aşağıdaki sonuçlar çıkarılabilir:

1. 13 yönündeki kayma modülündeki küçük artırımlar doğal frekansı düşürürken (negatif duyarlılık) diğer durumlarda temel doğal frekans artırma eğilimindedir.

2. Kayma gerilmelerindeki duyarlılık değerleri plaka kalınlığ 1 arttıkça sürekli olarak artma (Şekil $2 \mathrm{c}$ ve $2 \mathrm{~d}$ ) ya da azalma (Şekil 2e) gösterirken elastisite modüllerinde duyarlılık değerinde sürekli bir düzen görülmemiştir.
3. Fibere dik yöndeki elastisite modülündeki küçük artırımlar, fiber yönündeki elastisite modülündekilere göre temel doğal frekansı daha çok büyütmektedir yani daha büyük duyarlılık değerlerine sahiptir. $\mathrm{Bu}$ durum elastisite modüllerindeki düşük olan değerin artmasıyla birlikte plakanın direngenliğinin artmasıyla açıklanabilir.

4. İncelenen tasarım parametrelerinin duyarlıl1k genlikleri büyükten küçüğe doğru 13 yönündeki kayma gerilmesi, 12 yönündeki kayma gerilmesi, 
23 yönündeki kayma gerilmesi, fibere dik yöndeki elastisite modülü ve fiber yönündeki elastisite modülü olarak sıralanabilir. Buna göre temel doğal frekansın artırılması için temel olarak 13 yönündeki kayma gerilmesinin büyük olacağı bir plaka tasarımı yapılmalıdır.

5. Ayrıca bilindiği üzere genellikle kompozit plakaların doğal frekans analizleri sonucunda elde edilen deneysel sonuçlar ile sayısal sonuçlar arasinda genellikle farklılıklar meydana gelmektedir. Bu durum mekanik özelliklerin doğru olarak belirlenememesi ile açıklanmakta fakat hangi parametrenin doğru olarak elde edilemediği belirtilmemektedir. Burada görüldüğg̈ üzere, mekanik özellikler elde edilirken özellikle kayma modüllerinin doğru bir şekilde edilmesi son derece önemlidir.

\section{Sonuçlar}

$\mathrm{Bu}$ çalışmada dört farklı kalınlığa sahip basit mesnetli simetrik özel ortotropik katmanlı kompozit plakanın $\left(0^{0}, 90^{\circ}, 90^{\circ}, 0^{\circ}\right)$ temel doğal frekansının duyarlılık analizi gerçekleştirilmiştir. Tasarım parametreleri olarak fiber yönündeki ve fibere dik yöndeki elastisite modülleri ve üç yöndeki kayma modülleri seçilmiştir. temel doğal frekansın duyarlılı̆̆ının belirlenmesi için Monte Carlo simülasyonu sonuçlarına çok eğrili regresyon analizi (multiple curvilinear regression analysis) uygulanmıştır. Sonuç olarak kayma modüllerindeki küçük değişimlerin elastisite modüllerindekine göre temel doğal frekansı daha çok olarak etkilediği görülmüştür. Ayrıca 23 yönündeki kayma gerilmesindeki küçük artırımların doğal frekansı küçülttüğg̈ diğer parametrelerdeki artırımların ise temel doğal frekansı artırdığı gözlemlenmiştir.

\section{Kaynaklar}

Adelman, H. M. and Haftka, R. T. (1986). Sensitivity analysis of discrete structural systems. AIAA Journal, 24(5), 823-832. https://doi.org/10.2514/3.48671.

Arora, J. S. and Haugt, E. J. (1979). Methods of design sensitivity analysis in structural optimization. AIAA Journal, 17(9), 970-974. https://doi.org/10.2514/3.61260.

Dey, S., Mukhopadhyay, T. and Adhikari, S. (2015). Stochastic free vibration analysis of angle-ply composite plates - A RS-HDMR approach. Composite Structures, 122, 526-536. https://doi.org/10.1016/j.compstruct.2014.09.05 7.
Fox, R. L. and Kapoor, M. P. (1968). Rates of change of eigenvalues and eigenvectors. AIAA Journal, 6(12), 2426-2429. https://doi.org/10.2514/3.5008.

Grenestedt, J. L. (1989). Layup optimization and sensitivity analysis of the fundamental eigenfrequency of composite plates. Composite Structures, 12(3), 193-209. https://doi.org/10.1016/0263-8223(89)90022-6.

Hyer, M. W. and Lee, H. H. (1991). The use of curvilinear fiber format to improve buckling resistance of composite plates with central circular holes. Composite Structures, 18(3), 239261. https://doi.org/10.1016/02638223(91)90035-W.

Juhász, Z., Turcsán, T., Tóth, T. B. and Szekrényes, A. (2018). Sensitivity analysis for frequency based prediction of crack size in composite plates with through-the-width delamination. International Journal of Damage Mechanics, 27(6), 859-876. https://doi.org/10.1177/1056789517709893.

Kengtung, C. (1986). Sensitivity analysis and a mixed approach to the optimization of symmetric layered composite plates. Engineering Optimization, 9(4), 233-247. https://doi.org/10.1080/03052158608902516.

Khdeir, A. A. and Librescu, L. (1988). Analysis of symmetric cross-ply laminated elastic plates using a higher-order theory: Part II-Buckling and free vibration. Composite Structures, 9(4), 259$277 . \quad$ https://doi.org/10.1016/02638223(88)90048-7.

Kompella, M. S. and Bernhard, R. J. (1993). Measurement of the statistical variation of structural-acoustic characteristics of automotive vehicles. SAE Technical Paper 931272. https://doi.org/10.4271/931272.

Li, D. H., Liu, Y. and Zhang, X. (2013). Linear statics and free vibration sensitivity analysis of the composite sandwich plates based on a layerwise/solid-element method. Composite Structures, 106, 175-200. https://doi.org/10.1016/j.compstruct.2013.05.05 6.

Lima, A. M. G. d., Faria, A. W. and Rade, D. A. (2010). Sensitivity analysis of frequency response functions of composite sandwich plates containing viscoelastic layers. Composite Structures, $\quad 92(2), \quad 364-376$. https://doi.org/10.1016/j.compstruct.2009.08.01 7.

Mateus, H. C., Soares, C. M. M. and Soares, C. A. M. (1991). Sensitivity analysis and optimal design of thin laminated composite structures. Computers 
and Structures, 41(3), 501-508. https://doi.org/10.1016/0045-7949(91)90144-B.

Pouresmaeeli, S., Fazelzadeh, S. A., Ghavanloo, E. and Marzocca, P. (2018). Uncertainty propagation in vibrational characteristics of functionally graded carbon nanotube-reinforced composite shell panels. International Journal of Mechanical Sciences, 149, 549-558. https://doi.org/10.1016/j.ijmecsci.2017.05.049.

Pouresmaeeli, S. and Fazelzadeh, S. A. (2017). Uncertain buckling and sensitivity analysis of functionally graded carbon nanotube-reinforced composite beam. International Journal of Applied Mechanics, 9(5). https://doi.org/10.1142/S1758825117500715.

Soares, C. M. M., Correia, V. F., Mateus, H. and Herskovits, J. (1995). A discrete model for the optimal design of thin composite plate-shell type structures using a two-level approach. Composite
Structures,
$30(2)$,
$147-157$. https://doi.org/10.1016/0263-8223(94)00042-5.

Whitney, J. M. (1987). Structural analysis of laminated anisotropic plates. Pennsylvania: Technomic Publishing.

Zak, A. J., Cartmell, M. P. and Ostachowicz, W. M. (2003). A sensitivity analysis of the dynamic performance of a composite plate with shape memory alloy wires. Composite Structures, 60(2), 145-157. https://doi.org/10.1016/S02638223(02)00316-1.

Zhang, Z., Zhan, C., Shankar, K., Morozov, E. V., Singh, H. K. and Ray, T. (2017). Sensitivity analysis of inverse algorithms for damage detection in composites. Composite Structures, 176 ,

844-859. https://doi.org/10.1016/j.compstruct.2017.06.01 9. 